\title{
RATE OF INFORMATION PROCESSING AND REACTION TIME OF AIRCRAFT PILOTS AND NON-PILOTS
}

\author{
WERNER BARKHUIZEN \\ JOHANN SCHEPERS \\ Programme in Industrial Psychology \\ Department of Human Resource Management \\ Rand Afrikaans University \\ JOHAN COETZEE \\ Department of Industrial Psychology \\ University of Potchefstroom for Christian Higher Education
}

\begin{abstract}
Reaction time and rate of information processing are cited as critical components in the make-up of pilots. A need was identified to establish the validity of various chronometric measures in the selection of pilots. Fifty-eight military and commercial pilots and twenty non-pilots were subjected to Schepers' Computerised Information Processing Test Battery, which measures reaction time, form discrimination time, colour discrimination time, rate of information processing (perceptual) and rate of information processing (conceptual). Five hypotheses and one postulate were formulated and tested. The results indicate that pilots could be differentiated from non-pilots with 92,3\% accuracy. However, the results need to be cross-validated before they are used for selection.
\end{abstract}

\section{OPSOMMING}

Reaksietyd en tempo van inligtingverwerking word as kritieke komponente in die samestelling van vlieëniers beskou. ' $n$ Behoefte is geidentifiseer om die geldigheid van verskeie chronometriese metinge in vlieënierskeuring te bepaal. Agt en vyftig militêre en kommersiële vlieëniers en twintig nie-vlieëniers is onderwerp aan Schepers se Gerekenariseerde Inligtingverwerkingstoets-battery wat reaksietyd, vormdiskriminasietyd, kleurdiskriminasietyd, tempo van inligtingverwerking (perseptueel) en tempo van inligtingverwerking (konseptueel) meet. Vyf hipoteses en een postulaat is gestel en getoets. Die resultate dui daarop dat vlieëniers met $92,3 \%$ akkuraatheid van nievlieëniers onderskei kan word. Die resultate behoort egter eers gekruisvalideer te word voordat dit finaal vir keuring gebruik kan word.

Human error is cited as the main contributing factor in aircraft accidents. Swissair (1999) maintains that well over fifty percent of all aircraft accidents arise due to critical human error chains, and emphasises the reality that several unplanned scenarios plague pilots during flight. Professional piloting demands the proficient assimilation and manipulation of information received by the senses in order to respond effectively to dissimilar flight conditions.

Based on research done on 1448 German air force pilots, Gerbert and Kemmler (1987) suggest that a four-dimensional human error structure exists, comprising errors vigilance, perception, information processing, and sensorimotor actions that prove to be the main causes of aircraft accidents. Lack of experience with a specific aircraft type and the number of types presently flown contribute to aircraft accidents.

"Competent pilot performance is characterised by effective decisions in complex situations combined with relevant behaviours, quick planning, action, and suitable, well-timed corrections, applied in critical situations" (M-TWO, 1998, p. 1). It follows then that response conditioning and highly developed information processing schemes are critical for competent piloting. Moreover, responses to emergencies are dependent on the quality and the frequency of emergency procedure training. Repeated exposure to simulator emergency training creates a deposit of appropriate kinaesthetic responses that are memorised and retrieved subconsciously, almost instantly, when the pilot is confronted with similar bona fide emergency situations. Other factors that contribute to aircraft accidents are a lack of experience with a specific aircraft type as well as the number of types presently flown.

Requests for copies should be addressed to: $W$ Barkhuizen, Programme in Idustrial Psychology, Department of Human Resource Management, RAU, PO Box 524, Auckland Park, 2006
Flying demands a multifaceted combination of procedural, decisional and motor activities. Procedural activities consist of standard operating procedures and are dictated by the equipment characteristics. Secondly, whenever a condition arises in which there is uncertainty as to the likely result, the pilot makes predictions of the probable outcome based on the choices available and proceeds accordingly. These decisional activities are tremendously complex in the sense that an increase in uncertainty will ultimately lead to an increased probability of failure. Motor activities, such as manipulating the controls to change the orientation of the aircraft are usually continuous (Roscoe, 1980).

There are two distinct meteorological settings in aviation. In visual meteorological conditions, the pilot obtains primary information from the external environment. In addition, secondary information is derived from the instrument panel during certain phases of flight, for example, the airspeed and altitude indicators during take-off and landing. Instrument meteorological conditions, requires an absolute digression from conventional flying practice and necessitate heightened levels of attentiveness. Under these conditions, all the senses with the exception of sight, are disregarded. Decisions are based on instrument readings only and often conflict with the sense of balance, commonly referred to as spatial disorientation. Pilots frequently experience intrapersonal conflict due to established behavioural patterns and decisionmaking processes that have to be discarded in support of information received from the instrument panel. The brain processes the sensed information and decisions are generated to adjust the controls of the aircraft. Standard aircraft manoeuvring becomes a kinaesthetic and subconscious reaction. However, emergencies demand a combination of conscious decision-making and kinaesthetic responses aimed 
at managing the emergency and flying the aircraft. Accidents frequently occur during the transition from visual meteorological conditions to instrument meteorological conditions because pilots often change from instrument flight rules to visual flight rules prematurely, with devastating results because there are too few external cues available to complete the approach safely. Moisture in the air, rain or mist leads to a distortion of the visual field and may, for example, cause diffraction, for example, of the runway threshold lights. The typical approach path (ILS, VOR and VASIS) has a $3^{\circ}$ slope with the runway. Pilots are used to a "picture" of the runway. However, if the runway is positioned on a downhill slope, the "picture" will be dissimilar from the usual "picture". If the pilot flies the aircraft to perceive the same "picture" of the runway, the approach may be excessively steep. The same applies when a pilot is familiar with a particular runway and has to fly a difficult approach to an unfamiliar runway in bad weather or at night. The inclination will be to fly an approach that will ensure "ease" with the runway "picture" the pilot expects or wishes to see.

Schepers (1974) revealed that the major causes of undershoot accidents are that pilots failed to arrest a high sink rate timely, and did not succeed in determining the aircraft's correct position before initiating the descent. Accidents related to excessive sink rate typically occurr within four nautical miles of the runway threshold and accidents involving the inaccurate identification of the position of the aircraft seem to occurr within four to fifteen nautical miles from the runway threshold. It is important to note that all the pilots studied in these analyses were following instrument flight rules, and ILS*, $\operatorname{VOR}^{\dagger}$, and VASIS $^{\ddagger}$ were generally available. These examples suggest that pilots could be so involved with assimilating specific information, that they do not internalise, process or capture new information that becomes available. The aforesaid clearly indicates the importance of the senses in the overall proficiency of pilot information processing.

The human senses are the main receivers of information. Gagné (1985) maintains that explicit mental processes take place during information processing. Receptors encode stimuli from the external environment. Thereafter, patterns of neural impulses are generated and transmitted to a sensory register (Louw \& Edwards, 1993). Irrelevant stimuli, like background noise, are rejected and only useful stimuli are selected and utilised. Selected impulses are then transmitted to the shortterm memory and temporarily stored as auditory or visual images. Finally, the impulses are encoded semantically to ensure permanent storage in the long-term memory. When the need arises for a stored item, a search develops in the long-term memory, followed by a retrieval process. The senses obtain additional information, if necessary, to contrast with existing, stored information. Upon completion of this intricate compilation process, the brain arranges the information into a meaningful configuration to generate a realistic representation of the external environment (Louw \& Edwards, 1993). The information is transmitted to signal effectors, such as the hands, which perform the task. During the feedback and reinforcement phase, the mind observes the result of its performance and prepares to replicate the process, if appropriate (Gagné, 1985). To complete these tasks efficiently, humans rely on all their senses and higher intellectual abilities (Schepers, 1987).

"The sense of sight is the most specialised sense and equips pilots to obtain information from a distance" (Schepers, 1974, p. 14). Visual information reaches the pilot through the external environment and the instrument panel. Fixation often occurs when a pilot favours one instrument over another. For instance, airspeed may be perfect while a decrease in altitude remains unnoticed. Instrument training focuses on the reduction of fixation and emphasises the importance of well-organised instrument-scanning techniques. Results obtained in a study by
Williams (1995) indicate that young aviators with five months or less of flight training are predisposed to tunnel vision. However, their limited training protects them from excessive reduction in the field of vision reported by non-aviators.

Hearing enables the pilot to acquire a great deal of radio information on a probability basis due to a moderate amount of background noise (Schepers, 1974). Posner (1986) postulates that auditory reaction times are consistently faster than visual and tactile reaction times. Simpson and Marchionda-Frost (1985) suggest that future threat warning systems could warn pilots of other traffic and obstacles in the flight path during low-altitude helicopter flights. They found that reaction time improved significantly due to the threat warning messages. However, Burt, Bartolome, Burdette and Comstock (1995, p. 1) stress that "pilots are concerned about the lack of urgency of the signals employed by cockpit auditory warning systems. A correlation, linking the auditory warning sound parameters and perceived urgency of the warning tones should be established".

The sense of position and movement enables a person to walk, stand and execute any task requiring manual skill. All pilots should possess a well-developed kinaesthetic sense. The fingertips and tongue are best able to discriminate shape and texture. The synchronisation of the kinaesthetic and tactile sense enables the pilot to recognise the feel and texture of the controls and to affect the necessary amount of pressure on the controls unerringly to manoeuvre the aircraft safely. Balance, in conjunction with the kinaesthetic sense, inter alia helps the pilot to maintain the upright position as a critical frame of reference. Malcolm (1984) maintains that the semi-circular canals of the organs of balance have to stabilise the eyes in space during head movement. The otolith organs are responsible for providing a sense of direction during exposure to the G-vector during flight, which is imperative for efficient information processing. Over and above the senses, cognitive abilities play a significant role in successful airmanship.

Information processing is a function of intellectual ability that is representative of an individual's cognitive capacity (Vernon, 1987). Theoretical knowledge of flight provides a depository of information that guides the pilot's responses and actions in specific situations. If new information acquired from the external environment and the instrument panel is in conflict with stored information, the pilot's reaction time and rate of information processing are affected, which may lead to delayed or erroneous decisions.

Plug, Meyer, Louw and Gouws (1989, p. 155) define information processing as "the process whereby any system associates or transforms new information in order to align it with stored information, prior to the creation of new information. When an individual experiences a situation in which specific outcomes are required, a series of cognitive information processing stages are activated within the brain, which will eventually lead to a decision with positive or negative consequences. "Information processing represents a flow of information through a series of stages, similar to the operation of a computer" (Matlin, 1994, p. 7). Reaction time forms an integral part of the information processing scheme.

Kantowitz (1974, p. 44) defines reaction time as "the interval between the presentation of a stimulus to a subject and the subject's response". In operational terms, the interval is measured from the onset of the stimulus presentation to the initiation of the subject's response, in other words the latency of the response. Schepers (1987) remarks that if an individual is, for instance, required to press a button every time a light bulb lights up, a lapse in time will occur between the time the light bulb lights up and the individual's response. This lapse in time represents reaction time. Reaction time is thus a function of the information processing scheme. 
In the case of one button and one light bulb, the reaction time represents simple reaction time because no choice is involved. The individual responds by pressing the button when the light bulb lights up (Schepers, 1987). If an individual is presented with two different stimuli requiring a response to either the one or the other stimulus, the individual has to make a decision before the required response is executed. For example, if the individual is confronted with two light bulbs, each with its own button, and one of these light bulbs lights up, the individual has to decide which button to press. The individual's reaction time will be longer than with one light bulb because the simple reaction time is extended by the decision time. This represents choice reaction time. In complicating the issue by using four light bulbs, each light bulb with its own button, the individual's reaction time to a specific light bulb that lights up is further prolonged due to the choice of four alternatives. Choice reaction time is a function of the number of alternative responses available to the individual (Schepers, 1987). Several choices occur in flight, and a pilot's competency or success is a function of his ability to make the correct choice within the required time interval (Roscoe, 1980). Jonsson and Ricks (1993) suggested that the rate at which a large volume of information is processed serves as a predictive measure of a pilot's cognitive processing ability in different flight scenarios.

Schepers (1987) emphasises that it is possible to quantify the amount of information in each of the above situations, given that information is measured in binary digits or bits. Miller (1953) defines a bit as the amount of information required to halve uncertainty. In the above example, the individual had full knowledge of the situation, was confronted with one globe only and had to press a specific button. In the second instance, the individual had to choose between two alternatives, two light bulbs with two buttons. Hence, two alternative responses were likely. This represents one bit of information or $2^{1}$ alternatives (Schepers, 1987). Four light bulbs were presented to the individual in the third situation. A choice between four alternative responses is required and represents two bits of information or $2^{2}$ alternatives (Schepers, 1987). In mathematical terms, $\log _{2} \mathrm{~N}$ bits are required to solve $\mathrm{N}$ equi-probable choices (Miller, 1953). Lachmann, Lachmann and Butterfield (1979) postulate that an increase in the number of alternatives leads to an increase in uncertainty. Uncertainty depends not only on the number of alternatives, but also on the probability of each. According to Hick (1952), Hyman (1953) and Cummings (1964), reaction time is linearly related to the amount of information transmitted (measured in bits). Choice reaction time increases as the number of alternative responses increases. This linear relationship is valid only if the number of equi-probable responses is measured in bits.

Complexity is a precondition for demonstrating individual differences in cognitive ability and information processing. Several pilots fly aircraft in complete silence, while others freely discuss complex issues and retain the ability to function as competent pilots. A fallacy exists that some individuals can perform two tasks at the same time, whereas others need to focus all their attention on a specific task. It is not possible to perform two or more tasks simultaneously. In reality, the performance of the tasks oscillates rapidly between two or more tasks and creates the illusion of simultaneous performance. To perform two tasks at the same time would require extremely high rates of information processing from any individual (Schepers, 1987). Schweizer (1998) found that an increase in the number of cognitive operations led to a linear increase in mean reaction time. An increase in the complexity of cognitive operations causes task performance to reflect individual differences in cognitive abilities and the speed-ability relationship. Svensson, Angelborg-Thanderz, Sjoberg and Olsson (1997) found that low levels of information complexity influenced flight tasks, often leading to delays in the correction of, for example, altitude errors. Low-level flight at high- speed results in decreased precision due to an increase in informational load.
Due to an increase in informational load closer to the ground, the last phases of landing can generate high stress levels, which can in turn lead to increased reaction times. Schepers (1974) argues that pilots experience heavy workloads during the approach and landing phases of flight, particularly during instrument flight rules. Rate of decision-making is related to the reciprocal of reaction time - thus shorter reaction times permit more decisions per unit time. Rate of decision-making is therefore a function of the complexity of the available information (Schepers, 1987). According to Cummings (1964), the average, person is capable of processing three bits of information per second, without error. If the individual needs to process information at a rate higher than three bits per second, unavoidable rejection and "loss" of information occurs. If, however, the individual is highly experienced, information will be discarded selectively. However, the rate of information processing will differ from individual to individual, and Schepers (1974) maintains that highly skilled and experienced pilots can make complex decisions at a more leisurely rate than inexperienced pilots. Their reaction times might stay the same, but the number of decisions per unit time might increase. The individual differences also become apparent when one looks at reserve capacity.

According to Brown (1966), reserve capacity is the difference between the maximum rate of information processing (bits per second) of an individual, and the demand that the task requires (bits per second). If the difference is positive, it implies that the individual has a reserve capacity to perform other tasks if necessary. A negative difference implies that the workload is larger than the capacity of the individual. Rejection of information has to occur for the task to be executed effectively. "As tension and confusion mount under operational stress, large differences are revealed among pilots. The problem is to discover these differences early in the selection and training sequence" (Roscoe, 1980, p. 127). According to Brown (1966), a curvilinear relationship exists between stress level and vigilance. The completion of a task without stress or low stress will lead to a low level of vigilance within the individual. Vigilance increases with an increase in stress levels, but within limits. An optimal level of vigilance is associated with a specific stress level. Vigilance will decrease under excessive stress, because it immobilises the individual. Suffice it to say that the smaller the reserve capacity of an individual, the higher the level of stress the individual will experience in completing a task. Excessive stress leads to fatigue and reduces the capacity of the individual to process information effectively. Fontana (1990) maintains that excessive stress can lead to increased errors, a lowered level of concentration, and the development of irrational thought patterns. The flow of information during flight is a function of the flight rules, speed, distance, duration of the flight, aircraft type, crew and prevailing air traffic. Under visual meteorological conditions, pilots have more time to assess the situation and absorb new information from the environment. However, under instrument meteorological conditions, pilots are dependent on their instruments and limited, if any, external vision. The instruments serve as a primary information source and the external environment serves as an additional frame of reference.

According to Schepers (1987), there are marked individual differences in rate of information processing. Whenever the workload exceeds an individual's capacity, immobilisation occurs. Emotional and interpersonal conflict, poor crew resource management and conflict with the co-pilot or passengers lead to ineffective and sluggish information processing. Fatigue, sleep deprivation and drugs will dramatically influence the individual's ability to process information. Similarly, Van Tharp (1978) found that a significant performance deficit occurred in the reaction time of sleepdeprived individuals. With regard to emotional conflict, Harris (1997) maintains that several biases influence information processing. Current concerns tend to control an individual's 
perceptions and interpretations of incoming information. If a pilot is experiencing engine problems with an aircraft, ambiguous information will be interpreted as support for the diagnosis of engine problems.

Louw and Edwards (1993) maintain that the way in which individuals perceive a specific situation depends on their competence, experience and previous exposure to similar situations as well as their previous success or failure in those situations. Pilots rarely fail the tough commander course on account of a lack of flying skill or ability, but more often due to their personalities impacting on situational awareness, stress management and leadership (Swissair, 1999).

An example of the importance of efficient information processing is revealed in the case of the Robinson R22 helicopter. In the event of an engine failure, the pilot has approximately 1,5 seconds to react and lower the collective ${ }^{\ddagger}$ to initiate an autorotation $\$ \S$. If the pilot reacts too slowly, and the rotor $\mathrm{RPM} * * *$ drops to below $80 \%$, of the required rotor RPM, plus $1 \%$ for every 1000 feet of altitude, the helicopter will experience a catastrophic rotor stall (Robinson Helicopter Company, 1979).

The pilot serves as an information processing device interposed between the external environment, instrument panel and controls of the aircraft (Lachmann, Lachmann \& Butterfield, 1979), and the adequacy of the information is a function of the instruments at the pilot's disposal. Many hours of training and practice will establish effective instrument-scanning techniques that will ensure the proficient coding of information. It is important for instrument panels in different aircraft to be as similar as possible, since dissimilar instrument layouts will lead to deficient scanning patterns and cause accidents. Pilots will revert to well-known scanning patterns under stress and may misread information from an unfamiliar instrument display. On the other hand, radically different instrument layouts will produce less interference with the established habit (Schepers, 1974). "Logical and legible groupings of instruments lead to simplification and decrease the risk of misreading instruments as was the case with the old three-pointer altimeter" (Gagné, 1965 , p.175). Schepers (1974) concluded that a number of Boeing accidents occurred because pilots scanned only within the parameters of the " $\mathrm{T}$ " layout of the instrument panel. Pilots were unable to arrest the high sink rate of the aircraft due to their inability to read the VSI $\$ \ddagger \ddagger$ that falls outside the " $T$ " layout of the instrument panel. Underestimation of the probability of wind shear and compelling radio information also contributed to human error.

Technological advances in aircraft design necessitated the simplification of cockpit design and the programming of control functions to reduce pilot load and ultimately ensure safer aircraft. "As aircraft became faster, heavier, and more complex, instrument-reading errors became less tolerable" (Gagné, 1965, p.175). "The social and economic aspects of the aviation arena requires that the selection of optimal pilot training candidates include not only those who will pass the flight-training program, but also those who will have the greatest likelihood of success in their aviation career" (Koonce, 1996, p. 1). Pilots are exposed to longer international flights, increasing levels of traffic and equipment that is more complex and, therefore, dictates improved information processing and reaction times.

The basic requirements of the profession demand specific skills and attributes that include fast and efficient information processing and rapid, accurate reaction time. Critical assessment of the pilots' requisite level of information processing and reaction time, will ensure an objective method of pilot selection. In addressing this subject matter, the results of the present study may prove useful in pilot selection.
The specific objectives of this study are:

- To determine:

o the mean Choice reaction time,

- mean Form discrimination time,

- mean Colour discrimination time,

- mean Rate of information processing (Perceptual) and,

- mean Rate of information processing (Conceptual) of pilots of different aircraft types;

- To determine whether there are statistically significant correlations between:

o age,

o total number of flying hours,

- total number of flying hours on type,

- years of flying experience and Choice reaction time,

- Form discrimination time,

- Colour discrimination time,

- Rate of information processing (Perceptual) and

- Rate of information processing (Conceptual);

- To determine whether differences exist between pilots and non-pilots in respect of:

o Choice reaction time,

- Form discrimination time,

- Colour discrimination time,

- Rate of information processing (Perceptual) and

- Rate of information processing (Conceptual);

- To predict pilot vs. non-pilot group membership.

In view of the specific objectives of the study, the following five hypotheses and one postulate will be examined:

\section{Hypothesis 1}

Statistically significant differences in means exist between pilots of different aircraft types in respect of Choice reaction time, Form discrimination time, Colour discrimination time, Rate of information processing (Perceptual) and Rate of information processing (Conceptual).

\section{Hypothesis 2}

There are statistically significant positive correlations between age, total number of flying hours, number of flying hours on current type of aircraft and years of flying experience.

\section{Hypothesis 3}

There are statistically significant positive correlations between age, total number of flying hours, number of flying hours on current type and years of flying experience on the one hand, and scores on Choice reaction time, Form discrimination time, and Colour discrimination time on the other hand.

\section{Hypothesis 4}

There are statistically significant negative correlations between age, total number of flying hours, number of flying hours on current type and years of flying experience on the one hand, and the accuracy of responses in respect of Form discrimination time, Colour discrimination time, Rate of information processing (Perceptual) and Rate of information processing (Conceptual) on the other hand.

\section{Hypothesis 5}

Statistically significant differences in means exist between pilots and non-pilots in respect of Choice reaction time, Form discrimination time, Colour discrimination time, Rate of information processing (Perceptual) and Rate of information processing (Conceptual).

\section{Postulate 1}

The membership category, pilot vs. non-pilot, can be predicted with the aid of a stepwise canonical discriminant analysis, by using the various chronometric measures as predictors. 


\section{METHOD}

Sample

Due to limited access to, and time restrictions of, pilots, a convenience sample of military and commercial pilots was utilised. The pilot group was stratified according to age, years of flying experience, flying hours, and type of aircraft flown. For comparative purposes, a sample of nonpilots was drawn. The non-pilot sample consisted of individuals employed in fields unrelated to flying and had shown no interest or experience in flying. Care was taken to equate the mean age of the non-pilots with that of the pilots $[t(76)=0,913 ; p>0,30]$ and to ensure that both groups were of comparable educational level. As gender did not relate to the test scores of the pilot sample, [Hotelling's Trace (11 and $46)=0,150 ; p=0,797)]$, this variable was not strictly controlled in the selection of the comparison group. Table 1 summarises the means and standard deviations of the pilots and non-pilots in respect of age and the various measures of flying experience.

TABLE 1

MEANS AND STANDARD DEVIATIONS OF PILOTS AND NON-PILOTS IN RESPECT OF AGE AND VARIOUS MEASURES OF FLYING EXPERIENCE

\begin{tabular}{llrrrr}
\hline & & Mean & SD & Minimum & Maximum \\
\hline Pilots & Age & 28,72 & 7,78 & 21,00 & 50,00 \\
& Flying hours & 1810,00 & 2010,72 & 300,00 & 9000,00 \\
& Hours on type & 327,95 & 2277,42 & 12,00 & 3000,00 \\
& $\begin{array}{l}\text { Years of flying } \\
\text { experience }\end{array}$ & 8,00 & 15,69 & 1,00 & 26,00 \\
& & 31,75 & 10,20 & 23,00 & 53,00 \\
\hline
\end{tabular}

From an inspection of Table 1 , it is clear that in the case of pilots, their mean age was 28,72 years and the standard deviation 7,78 years. The minimum age was 21,00 and the maximum 50,00 years. The mean for flying experience was 8,00 years and the standard deviation 15,69 years. The maximum number of years of flying experience was 26,00 years and the minimum, one-year.

In terms of number of flying hours, the mean was 1810,00 hours and the standard deviation 2010,72 hours. The maximum number of flying hours was 9000,00 hours and the minimum 300,00 hours. The mean for hours on type was 327,95 hours and the standard deviation 2277,42. The minimum number of hours on type was 12,00 hours and the maximum 3000,00 hours.

In many cases, the pilots are rated on three different types of aircraft. It was decided to use, current type mostly flown, as the basis for differentiating between the pilots. Aircraft types flown included the Lockheed C130, Cessna Citation, Hawker Siddeley, King Air, Cessna Caravan, Cessna 182, Casa 212, Oryx and Allouette helicopters.

The minimum academic qualification of the pilot group was matric with mathematics and science. The highest qualification of the pilot group was a master's degree. The pilot group comprised 53 men and 5 women.

In the case of non-pilots, the mean age was 31,75 years and the standard deviation 10,20 years. The minimum age was 23,00 years and the maximum 53,00 years. The minimum academic qualification was matric with mathematics and science. The highest academic qualification of the non-pilot group was an honours degree. The non-pilot group consisted of 12 men and 8 women.

\section{Measuring Instruments}

The objective assessment of reaction time and information processing requires appropriate measuring instruments. Schepers' Computerised Information Processing Test Battery (2001) was chosen for this purpose. The Computerised Information Processing Test Battery is an adaptation of tests used to perform pilot selection within the South African Air Force (Schepers, 1966) and further work is currently being done by Schepers. The test battery consists of five chronometric tests that are administered by means of a TouchScreen Computer System.

The tests are:

1. Choice reaction time;

2. Form discrimination time;

3. Colour discrimination time;

4. Rate of information processing (Perceptual);

5. Rate of information processing (Conceptual).

According to the manual of Schepers' Computerised Information Processing Test Battery (2001), the following scores, based on a series of factor analyses, are relevant:

1. Reaction time: Factor 1;

2. Reaction time: Factor 2;

3. Form discrimination time: Accuracy;

4. Form discrimination time: Decision time;

5. Form discrimination time: Response time;

6. Colour discrimination time: Accuracy;

7. Colour discrimination time: Decision time;

8. Colour discrimination time: Response time;

9. Rate of information processing (Perceptual);

10. Rate of information processing (Conceptual): Factor 1;

11. Rate of information processing (Conceptual): Factor 2.

It is important to note that due to time constraints it was necessary to reduce the number of stimuli of both the Rate of information processing (Perceptual) and Rate of information processing (Conceptual) tests from 30 to 10. Each test consists of six series and each series is presented at a different rate, varying from 2000 milliseconds to 1000 milliseconds. The total number of stimuli of each test was thus reduced from 180 to 60 .

\section{RESULTS}

Before the main statistical analysis was undertaken, it was decided to ascertain whether the pilot sample should be used as a single sample or whether it was necessary to differentiate between the various groups in terms of aircraft type flown.

As far as the pilots of different aircraft types were concerned, it was hypothesised that their mean scores differ in terms of the various chronometric measures. Accordingly, a multiple analysis of variance (MANOVA) was done to ascertain whether there are overall differences in mean scores. Wilks' Lambda was 0,348 . This coefficient was statistically non-significant. [F (44, $166,462)=1,202 ; p=0,204]$ and hypothesis 1 was therefore rejected. Accordingly, it was decided to treat the pilot sample as a single sample and not to differentiate groups in terms of aircraft type flown.

In order to test hypotheses 2,3 and 4 , the various chronometric measures were correlated with age, total number of flying hours, number of hours on current type, and years of flying experience. The matrix of intercorrelations of the chronometric measures jointly with age and measures of flying experience is given in Table 2 .

From an inspection of Table 2, it is clear that there is a positive correlations between age and Reaction time: Factor 1, Reaction time: Factor 2, Form discrimination time: Response time and Colour discrimination time: Response time. With regards to total number of flying hours, a positive correlation 
TABLE 2

MATRIX OF INTERCORRELATIONS OF CHRONOMETRIC MEASURES JOINTLY WITH AGE AND MEASURES OF FLYING EXPERIENCE

\begin{tabular}{|c|c|c|c|c|c|c|c|c|c|c|c|c|c|c|c|c|}
\hline No. & Variables & 1 & 2 & 3 & 4 & 5 & 6 & 7 & 8 & 9 & 10 & 11 & 12 & 13 & 14 & 15 \\
\hline 1 & Age & 1,000 & 0,909 & 0,416 & 0,962 & $0,271^{*}$ & $0,341^{*}$ & 0,058 & $-0,102$ & $0,251^{*}$ & 0,117 & $-0,036$ & 0,239 * & $-0,265^{*}$ & $-0,180$ & $-0,298$ * \\
\hline 2 & Total number of flying hours & 0,909 & 1,000 & 0,550 & 0,940 & 0,195 & $0,248^{*}$ & 0,097 & $-0,095$ & $0,215^{*}$ & 0,046 & $-0,023$ & 0,179 & $-0,229^{*}$ & $-0,163$ & $-0,254$ * \\
\hline 3 & Number of flying hours on current type & 0,416 & 0,550 & 1,000 & 0,440 & 0,048 & 0,088 & 0,071 & 0,008 & 0,061 & 0,100 & $-0,011$ & 0,137 & $-0,103$ & $-0,132$ & 0,032 \\
\hline 4 & Years of flying experience & 0,962 & 0,940 & 0,440 & 1,000 & $0,298^{*}$ & 0,372 * & 0,161 & $-0,121$ & $0,249^{*}$ & 0,133 & $-0,023$ & 0,211 * & $-0,265^{*}$ & $-0,144$ & $-0,244^{*}$ \\
\hline 5 & Reaction time: Factor 1 & $0,271^{*}$ & 0,195 & 0,048 & $0,298^{*}$ & 1,000 & 0,663 & 0,201 & 0,059 & 0,096 & 0,337 & 0,146 & 0,040 & 0,022 & $-0,178$ & 0,069 \\
\hline 6 & Reaction time: Factor 2 & 0,341 * & $0,248^{*}$ & 0,088 & $0,372^{*}$ & 0,663 & 1,000 & 0,121 & 0,110 & 0,192 & 0,217 & 0,186 & 0,161 & $-0,115$ & $-0,130$ & $-0,233$ \\
\hline 7 & Form discrimination time: Accuracy & 0,058 & 0,097 & 0,071 & 0,161 & 0,201 & 0,121 & 1,000 & 0,017 & $-0,034$ & 0,323 & 0,103 & $-0,042$ & $-0,052$ & 0,028 & 0,250 \\
\hline 8 & Form discrimination time: Decision time & $-0,102$ & $-0,095$ & 0,008 & $-0,121$ & 0,059 & 0,110 & 0,017 & 1,000 & $-0,632$ & 0,068 & 0,749 & $-0,334$ & $-0,213$ & $-0,241$ & $-0,192$ \\
\hline 9 & Form discrimination time: Response time & 0,251 * & $0,215^{*}$ & 0,061 & 0,249 * & 0,096 & 0,192 & $-0,034$ & $-0,632$ & 1,000 & 0,044 & $-0,601$ & 0,766 & $-0,099$ & 0,037 & $-0,124$ \\
\hline 10 & Colour discrimination time: Accuracy & 0,117 & 0,046 & 0,100 & 0,133 & 0,337 & 0,217 & 0,323 & 0,068 & 0,044 & 1,000 & $-0,053$ & 0,126 & 0,067 & 0.000 & 0,143 \\
\hline 11 & Colour discrimination time: Decision time & $-0,036$ & $-0,023$ & $-0,011$ & $-0,023$ & 0,146 & 0,186 & 0,103 & 0,749 & $-0,601$ & $-0,053$ & 1,000 & $-0,626$ & $-0,166$ & $-0,267$ & $-0,196$ \\
\hline 12 & Colour discrimination time: Response time & 0,239 * & 0,179 & 0,137 & $0,211^{*}$ & 0,040 & 0,161 & $-0,042$ & $-0,334$ & 0,766 & 0,126 & $-0,626$ & 1,000 & $-0,248$ & $-0,018$ & $-0,141$ \\
\hline 13 & Rate of information processing (Perceptual) & $-0,265^{*}$ & $-0,229 *$ & $-0,103$ & $-0,265$ & 0,022 & $-0,115$ & $-0,052$ & $-0,213$ & $-0,099$ & 0,067 & $-0,166$ & $-0,248$ & 1,000 & 0,334 & 0,283 \\
\hline 14 & $\begin{array}{l}\text { Rate of information processing (Conceptual): } \\
\text { Factor } 1\end{array}$ & $-0,180$ & $-0,163$ & $-0,132$ & $-0,144$ & $-0,178$ & $-0,130$ & 0,028 & $-0,241$ & 0,037 & 0.000 & $-0,267$ & $-0,018$ & 0,334 & 1,000 & 0,332 \\
\hline 15 & $\begin{array}{l}\text { Rate of information processing (Conceptual): } \\
\text { Factor } 2\end{array}$ & $-0,298^{*}$ & $0,254^{*}$ & 0,032 & $-0,244$ & 0,069 & $-0,233$ & 0,25 & $-0,192$ & $-0,124$ & 0,143 & $-0,196$ & $-0,141$ & 0,283 & 0,332 & 1,000 \\
\hline
\end{tabular}

Note

$r=0,220 ; d f=55 ; p=0,05 \quad\}$ one - tailed

$r=0,261 ; \quad p=0,025\}$ one - tailed

$r=0,307 ; \quad p=0,01 \quad\}$ one - tailed

$r=0,339 ; \quad p=0,005\}$ one - tailed

was obtained between total number of flying hours, Reaction time: Factor 2 and Form discrimination time: Response time. Negative correlation were obtained with Rate of information processing (Perceptual) and Rate of information processing (Conceptual): Factor 2. None of the measures correlated with hours on current type. Positive correlations were found between years of flying experience and Reaction time: Factor 1, Reaction time: Factor 2, Form discrimination time: Response time and Colour discrimination time: Response time. Negative correlation with Rate of information processing (Perceptual) and Rate of information processing (Conceptual): Factor 2 were obtained. Hence, hypotheses 2, 3 and 4 are partially supported by the results.

Table 3 concerns the means and standard deviations of pilots and non-pilots in respect of the various chronometric measures.
TABLE 3

MEANS AND STANDARD DEVIATIONS OF PILOTS AND NON-PILOTS IN RESPECT OF THE CHRONOMETRIC MEASURES

\begin{tabular}{|c|c|c|c|}
\hline Variables & Group & Mean & $\begin{array}{c}\text { Standard } \\
\text { Deviation }\end{array}$ \\
\hline Reaction time: Factor 1 & $\begin{array}{l}\text { Pilots } \\
\text { Non-Pilots } \\
\text { Total }\end{array}$ & $\begin{array}{l}3677,64 \\
4231,23 \\
3819,59\end{array}$ & $\begin{array}{l}396,06 \\
825,82 \\
586,17\end{array}$ \\
\hline Reaction time: Factor 2 & $\begin{array}{l}\text { Pilots } \\
\text { Non-Pilots } \\
\text { Total }\end{array}$ & $\begin{array}{l}2988,88 \\
3559,58 \\
3135,21\end{array}$ & $\begin{array}{l}324,40 \\
557,11 \\
466,25\end{array}$ \\
\hline Form discrimination time: Accuracy & $\begin{array}{l}\text { Pilots } \\
\text { Non-Pilots } \\
\text { Total }\end{array}$ & $\begin{array}{l}96,55 \\
90,50 \\
95,00\end{array}$ & $\begin{array}{l}3,85 \\
5,44 \\
5,03\end{array}$ \\
\hline Form discrimination time: Decision time & $\begin{array}{l}\text { Pilots } \\
\text { Non-Pilots } \\
\text { Total }\end{array}$ & $\begin{array}{l}899,31 \\
364,01 \\
762,05\end{array}$ & $\begin{array}{l}564,02 \\
110,96 \\
542,10\end{array}$ \\
\hline Form discrimination time: Response time & $\begin{array}{l}\text { Pilots } \\
\text { Non-Pilots } \\
\text { Total }\end{array}$ & $\begin{array}{l}1052,35 \\
1151,43 \\
1077,75\end{array}$ & $\begin{array}{l}581,25 \\
269,27 \\
519,51\end{array}$ \\
\hline Colour discrimination time: Accuracy & $\begin{array}{l}\text { Pilots } \\
\text { Non-Pilots } \\
\text { Total }\end{array}$ & $\begin{array}{l}94,65 \\
88,67 \\
93,12\end{array}$ & $\begin{array}{l}4,99 \\
6,43 \\
5,97\end{array}$ \\
\hline Colour discrimination time: Decision time & $\begin{array}{l}\text { Pilots } \\
\text { Non-Pilots } \\
\text { Total }\end{array}$ & $\begin{array}{l}999,61 \\
364,29 \\
836,71\end{array}$ & $\begin{array}{l}595,08 \\
92,03 \\
584,97\end{array}$ \\
\hline Colour discrimination time: Response time & $\begin{array}{l}\text { Pilots } \\
\text { Non-Pilots } \\
\text { Total }\end{array}$ & $\begin{array}{l}1224,68 \\
1376,66 \\
1263,65\end{array}$ & $\begin{array}{l}759,09 \\
289,29 \\
672,06\end{array}$ \\
\hline Rate of information processing (Perceptual) & $\begin{array}{l}\text { Pilots } \\
\text { Non-Pilots } \\
\text { Total }\end{array}$ & $\begin{array}{l}503,79 \\
466,00 \\
494,10\end{array}$ & $\begin{array}{l}85,12 \\
85,13 \\
86,18\end{array}$ \\
\hline $\begin{array}{l}\text { Rate of information processing (Conceptual): } \\
\text { Factor } 1\end{array}$ & $\begin{array}{l}\text { Pilots } \\
\text { Non-Pilots } \\
\text { Total }\end{array}$ & $\begin{array}{l}205,69 \\
204,00 \\
205,26\end{array}$ & $\begin{array}{l}44,88 \\
50,10 \\
45,95\end{array}$ \\
\hline $\begin{array}{l}\text { Rate of information processing (Conceptual): } \\
\text { Factor } 2\end{array}$ & $\begin{array}{l}\text { Pilots } \\
\text { Non-Pilots } \\
\text { Total }\end{array}$ & $\begin{array}{l}195,69 \\
223,50 \\
202,82\end{array}$ & $\begin{array}{l}49,95 \\
49,23 \\
50,94\end{array}$ \\
\hline
\end{tabular}

Note

Pilots: $\mathrm{N}=58$

Non-pilots: $\mathrm{N}=20$ 
A multiple analysis of variance (MANOVA) was performed in order to ascertain whether the vectors of means of the pilots and non-pilots differ from one another. Table 4 provides a comparison of the vectors of means of the pilots and non-pilots in respect of the various chronometric measures.

TABLE 4

MANOVA: COMPARISON OF THE VECTORS OF MEANS OF PILOTS AND NON-PILOTS IN RESPECT OF THE CHRONOMETRIC MEASURES

\begin{tabular}{|c|c|c|c|c|c|c|}
\hline \multirow{2}{*}{ Effect } & & \multicolumn{2}{|c|}{ Hypothesis } & \multicolumn{2}{|c|}{ Error } & \multirow[b]{2}{*}{$\mathrm{p}$} \\
\hline & & Value & F & df & df & \\
\hline \multirow[t]{4}{*}{ Intercept } & Pillai's Trace & 0,998 & 3495,289 & 11 & 66 & $<0,001$ \\
\hline & Wilks' Lambda & 0,002 & 3495,289 & 11 & 66 & $<0,001$ \\
\hline & Hotelling's Trace & 582,548 & 3495,289 & 11 & 66 & $<0,001$ \\
\hline & Roy's Largest Root & 582,548 & 3495,289 & 11 & 66 & $<0,001$ \\
\hline \multirow[t]{4}{*}{ Group } & Pillai's Trace & 0,664 & 11,875 & 11 & 66 & $<0,001$ \\
\hline & Wilks' Lambda & 0,336 & 11,875 & 11 & 66 & $<0,001$ \\
\hline & Hotelling's Trace & 1,979 & 11,875 & 11 & 66 & $<0,001$ \\
\hline & Roy's Largest Root & 1,979 & 11,875 & 11 & 66 & $<0,001$ \\
\hline
\end{tabular}

$\mathrm{p}=<0.001$

From an inspection of Table 4, it is clear that Wilks' Lambda $(0,336)$ is statistically highly significant $[\mathrm{F}(11,66)=11,875 ; \mathrm{p}<$ $0,001]$.

Next, an analysis of variance (ANOVA) was performed in order to compare the means of the pilots and non-pilots in respect of each of the chronometric measures. The results are given in Table 5 . minimum of ten cases in the smallest group is recommended (Cliff, 1987, p. 409).

As far as the normality assumptions are concerned, Cliff (1987, p. 409) is of the opinion that (within limits) these assumptions are not very important. As far as the homogeneity of the variance-covariance matrices is concerned, Cliff (1987, p. 409) maintains that "nearly every example based on real data seems to show clear evidence of heterogeneity of variance on the canonical variate...". To overcome this problem, he recommends that we rely on "the services of that patient workhorse known as cross-validation".

In order to test the assumption of equality of the variancecovariance matrices of the pilots and non-pilots, Box's test of equality of covariance matrices was used. The results of Box's test are provided in Table 6.

TABLE 6

BOX'S TEST OF EOUALITY OF COVARIANCE MATRICES

\begin{tabular}{lcc}
\hline \multicolumn{1}{c}{ Group } & Rank & Log Determinant \\
\hline Pilots & 4 & 39,577 \\
Non-Pilots & 4 & 36,514 \\
Pooled within-groups & 4 & 39,801 \\
\hline & & \\
\hline Box's M & & 75,167 \\
F & Approx. & 6,89 \\
& df1 & 10 \\
& df2 & 5896,2 \\
& p & $<0,001$
\end{tabular}

TABLE 5

COMPARISON OF THE MEANSOF THE PILOTS AND NON-PILOTS IN RESPECT OF THE CHRONOMETRIC MEASURES

\begin{tabular}{|c|c|c|c|c|c|c|}
\hline Source & Variable & TypeIII Sum of Squares & df & Mean Square & $\mathrm{F}$ & $\mathrm{p}$ \\
\hline \multirow[t]{11}{*}{ Group } & Reaction Time: Factor 1 & 4557656,789 & 1 & 4557656,789 & 15,817 & $<0,001$ \\
\hline & Reaction Time: Factor 2 & 4843647,967 & 1 & 4843647,967 & 30,946 & $<0,001$ \\
\hline & Form discrimination time: Accuracy & 544,686 & 1 & 544,686 & 29,449 & $<0,001$ \\
\hline & Form discrimination time: Decision time & 4261398,854 & 1 & 4261398,854 & 17,634 & $<0,001$ \\
\hline & Form discrimination time: Response time & 145993,957 & 1 & 145993,957 & 0,538 & 0,466 \\
\hline & Colour discrimination time: Accuracy & 532,998 & 1 & 532,998 & 18,351 & $<0,001$ \\
\hline & Colour discrimination time: Decision time & 6002708,226 & 1 & 6002708,226 & 22,422 & $<0,001$ \\
\hline & Colour discrimination time: Response time & 343502,980 & 1 & 343502,980 & 0,758 & 0,387 \\
\hline & Rate of information processing (Perceptual) & 21241,620 & 1 & 21241,620 & 2,932 & 0,091 \\
\hline & Rate of information processing (Conceptual): Factor 1 & 42,458 & 1 & 42,458 & 0,020 & 0,888 \\
\hline & Rate of information processing (Conceptual): Factor 2 & 11052,073 & 1 & 11052,073 & 4,643 & 0,034 \\
\hline
\end{tabular}

From an inspection of Table 5, it is clear that Reaction time: Factor 1, Reaction time: Factor 2, Form discrimination time: Accuracy, Form discrimination time: Decision time, Colour discrimination time: Accuracy, Colour discrimination time: Decision time and Rate of information processing (Conceptual): Factor 2 differ statistically and significantly between aircraft pilots and non-pilots. Hypothesis 5 was therefore largely supported.

In view of the obtained differences, it was decided to do a stepwise canonical discriminant analysis in order to ascertain how well the membership category of pilot vs. non-pilot could be predicted with the aid of the various chronometric measures.

Canonical discriminant analysis is based on the following assumptions:

- That each of the variables in respect of each of the populations compared should have a multivariate normal distribution (SPSS, Inc, 1999, pp. 248-249);

- That the variance-covariance matrices of the various populations compared should be equal (Bennett \& Bowers, 1976, pp. 95-96; Cliff, 1987, pp. 408-409); and

- That the samples compared, are of adequate size - a
From the results, it is clear that the two variance-covariance matrices differ statistically and significantly from one another. This implies a violation of one of the assumptions of canonical discriminant analysis. This violation might well disturb the validity of the present study, but if the predictions hold when the classification function coefficients are cross-validated on a future sample, more confidence can be placed in the outcome of the present study.

The eleven different scores of Schepers' Computerised Information Processing Test Battery served as input to the stepwise canonical discriminant analysis.

The following four variables were included in the canonical discriminant function:

1. Reaction time: Factor 2;

2. Colour discrimination time: Decision time;

3. Colour discrimination time: Accuracy; and

4. Form discrimination time: Response time.

Wilks' Lambda coefficients, in respect of the aforementioned variables, are given in Table 7.

From an inspection of Table 7 , it is clear, that all the Wilks' Lambda coefficients are statistically highly significant. The 
TABLE 7

VARIABLES ENTERED

\begin{tabular}{|c|c|c|c|c|c|c|c|c|c|c|}
\hline \multirow[b]{2}{*}{ Step } & \multirow[b]{2}{*}{ Entered } & \multirow[b]{2}{*}{ Removed } & \multicolumn{8}{|c|}{ Wilks' Lambda } \\
\hline & & & Statistic & df1 & df2 & df3 & Statistic & df1 & $\begin{array}{l}F \\
\text { df } 2\end{array}$ & $\mathrm{p}$ \\
\hline 1 & Reaction time: Factor 2 & & 0,711 & 1 & 1 & 76 & 30,946 & 1 & 76 & $<0,001$ \\
\hline 2 & Form discrimination time: Response time & & 0,406 & 4 & 1 & 76 & 26,728 & 4 & 73 & $<0,001$ \\
\hline 3 & Colour discrimination time: Accuracy & & 0,458 & 3 & 1 & 76 & 29,215 & 3 & 74 & $<0,001$ \\
\hline 4 & Colour discrimination time: Response time & & 0,552 & 2 & 1 & 76 & 30,457 & 2 & 75 & $<0,001$ \\
\hline
\end{tabular}

coefficients vary from 0,406 to 0,711 . Small values indicate strong group differences whereas values close to 1,0 indicate no differences (SPSS, Inc., 1999, p. 252).

The pilot and non-pilot groups can be differentiated by means of the classification function coefficients given in Table 8 .

TABLE 8

Classification FUnCtion COEFFicients

\begin{tabular}{lcc}
\hline & \multicolumn{2}{c}{ Group } \\
& Pilots & Non-Pilots \\
\hline Reaction time: Factor 2 & 0,012 & 0,017 \\
Form discrimination time: Response time & 0,004 & 0,001 \\
Colour discrimination time: Accuracy & 3,156 & 2,897 \\
Colour discrimination time: Decision time & 0,006 & 0,001 \\
Constant & $-173,058$ & $-161,104$ \\
\hline
\end{tabular}

The discriminant functions for the pilots and non-pilots are as follows:

Pilots (X): $0,012 \mathrm{X}_{1}+0,004 \mathrm{X}_{2}+3,156 \mathrm{X}_{3}+0,006 \mathrm{X}_{4}-173,058$

Non-pilots (Y): $0,017 \mathrm{X}_{1}+0,004 \mathrm{X}_{2}+2,897 \mathrm{X}_{3}+0,001 \mathrm{X}_{4}-161,104$

A participant is predicted as being a member of the group (pilot or non-pilot) for which his/her classification function yields the largest value.

Alternatively, Fisher's Linear Discriminant Function can be used to classify the participants as pilots or non-pilots. Fisher's Linear Discriminant Function can be computed as follows: Take the difference between the classification function coefficients of the pilots and non-pilots (SPSS, Inc., 1999, p. 254).

$Z=(0,012-0,017) X_{1}+(0,004-0,001) X_{2}$

$+(3,156-2,897) X_{3}+(0,006-0,001) X_{4}$

$+(-173,058+161,104)$

$Z=-0,005 X_{1}+0,003 X_{2}+0,259 X_{3}+0,005 X_{4}-11,954$, where

$\mathrm{X}_{1}=$ Reaction time: Factor 2;

$\mathrm{X}_{2}=$ Colour discrimination time: Decision time;

$\mathrm{X}_{3}=$ Colour discrimination time: Accuracy, and

$\mathrm{X}_{4}=$ Form discrimination time: Response time.

A positive $\mathrm{Z}$ value leads to classification as a pilot, whereas a negative score leads to non-pilot classification. This follows logically from the fact that $\mathrm{Z}=\mathrm{X}-\mathrm{Y}$.

The centroids in respect of the aircraft pilots and non-pilots were calculated by means of the discriminant functions: The pilots obtained a value of 0,701 and the non-pilots a value of $-2,034$.

A participant can be classified as a pilot or non-pilot on the basis of the discriminant score. If the score is closest to the centroid of the pilots, classification as a pilot follows. If the participant's score is, however, closest to the centroid of the non-pilots, the classification will be as a non-pilot.

The relative weights of each variable in the canonical discriminant function are given by the standardised canonical discriminant function coefficients given in Table 9.

TABle 9

STANDARDISED CANONICAL DISCRIMINANT FUNCTION COEFFICIENT

\begin{tabular}{lc}
\hline & Function \\
& $\mathbf{1}$ \\
\hline Reaction time: Factor 2 & $-0,809$ \\
Form discrimination time: Response time & 0,562 \\
Colour discrimination time: Accuracy & 0,511 \\
Colour discrimination time: Response time & 0,903 \\
\hline
\end{tabular}

From Table 9, it is clear that the weights vary from 0,511 to 0,903 . Colour discrimination time: Response time $(0,903)$ carries the most weight.

It should be kept in mind that these are the weights that the variables carry in the canonical discriminant function and do not necessarily signify the importance of these attributes in the characteristics of the subjects that are compared with one another. The correlations of the discriminant function with each of the discriminating variables are given in the structure matrix, which is shown in Table 10 .

TABLE 10 STRUCTURE MATRIX

\begin{tabular}{lc}
\hline & Function \\
& $\mathbf{1}$ \\
\hline Reaction time: Factor 2 & $-0,527$ \\
Colour discrimination time: Decision time & 0,449 \\
Colour discrimination time: Accuracy & 0,406 \\
Form discrimination time: Accuracy (a) & 0,309 \\
Form discrimination time: Decision time (a) & 0,294 \\
Reaction time: Factor 1 (a) & $-0,283$ \\
Rate of information processing (Conceptual): Factor 1 (a) & $-0,212$ \\
Colour discrimination time: Response time (a) & $-0,164$ \\
Rate of information processing (Perceptual) (a) & 0,070 \\
Form discrimination time: Response time & 0,070 \\
Rate of information processing (Conceptual): Factor 2 (a) & 0,070 \\
\hline
\end{tabular}

Pooled within-groups correlations between discriminating variables and standardised canonical discriminant function.

Variables ordered according to absolute size of correlation with function.

a. These variables not used in the analysis.

These correlations indicate that Reaction time: Factor 2, Colour discrimination time: Decision time, Colour discrimination time: Accuracy, Form discrimination time: Accuracy, Form discrimination time: Decision time, and Reaction time: Factor 1 are the most important variables in the make-up of pilots.

The classification results are given in Table 11. 
TABLE 11

Classification results

\begin{tabular}{lccccc}
\hline & \multicolumn{4}{c}{ Predicted Group } & \\
& & Group & Pilots & Non-Pilots & Total \\
\hline \multirow{2}{*}{ Original } & \multirow{2}{*}{ Frequency } & Pilots & 54 & 4 & 58 \\
& & Non-Pilots & 2 & 18 & 20 \\
\hline & $\%$ & Pilots & 93,1 & 6,9 & \multirow{2}{*}{100} \\
\hline \multirow{2}{*}{ Original } & $\%$ & Non-Pilots & 10.0 & 90.0 & 100 \\
& &
\end{tabular}

$92,3 \%$ of orginal cases correctly classified

From an inspection of Table 11, it is clear that by using the variables included in the discriminant function, a highly accurate classification of pilots and non-pilots can be obtained. In the case of pilots, $93 \%$ were correctly classified as pilots and $90 \%$ of the non-pilots were correctly classified. An overall accuracy of $92,3 \%$ was obtained in terms of this classification.

\section{DISCUSSION}

No differences exist between pilots of different aircraft types, which implies that a generic response profile applies to pilots in terms of the information processing and reaction time measures.

The correlation between age and the scores on the three reaction time measures confirms that reaction time is a function of age (Table 2). Braune and Wickens (1986) conclude that spatial ability, dichotic listening and perceptual-motor co-ordination decrease together with reaction time in pilots beyond the age of forty.

In addition, accuracy of responses is a function of age. The negative correlation between age and accuracy of responses in respect of Form discrimination time and Colour discrimination time as well as both information processing measures implies that accuracy decreases as age increases. Furthermore, from Table 3, it is evident that the accuracy of the Form discrimination time and Colour discrimination time measures of pilots is higher than that of non-pilots. Non-pilots seem to trade-off accuracy in favour of faster decision times in the case of Form discrimination time and Colour discrimination time. The decision time of pilots is longer, but they obtain greater accuracy and faster response time than non-pilots. Lachmann, Lachmann and Butterfield (1979) stated that pilots read and interpret instrument readings, whereafter they decide which controls to manipulate. This suggests that pilots assimilate all the information, assess the correctness thereof and then apply the decision with an expeditious response. Schweizer (1996) indicates that individual differences in reaction time and accuracy tend to increase with an intensification of the complexity of tasks. A reduction in reaction time demands leads to lower correlations between accuracy and cognitive abilities. The above findings could be attributed to pilot training techniques - pilots are trained to assimilate, assess and then respond.

Should these findings be supported under cross-validation, it would be possible to distinguish pilots from non-pilots with $92,3 \%$ accuracy, based on the discriminant score. The following variables are the most important in the make-up of pilots and statistically significant differences exist between the means of pilots and non-pilots in respect of: Reaction time: Factor 2, Colour discrimination time: Decision time, Colour discrimination time: Accuracy and Form discrimination time: Response time. The strongest weight is carried by Colour discrimination time: Response time carries the most weight $(0,903)$. However, this does not signify the importance of this attribute in the make-up of pilots and non-pilots. Once again, the fact that pilots are trained to make slower decisions combined with accurate responses could influence their response times. Since there is inadequate research in this regard, it is difficult to compare the outcome of the present study with other studies. As far as information processing is concerned, reaction time studies focus predominantly on flight deck development, analogue vs. digital displays, auditory and visual reaction time, and the influence of sleep-deprivation, alcohol and other substances on reaction time measures. Furthermore, several researchers focus on reaction time measures and intelligence as well as information processing strategies as predictors of accident involvement.

Several studies have focused on the influence of anticipation on information processing and reaction time. Verbal cues (Shingledecker, 1979), advance information (Remington, 1971), countdown procedures (Simon and Slaviero, 1975) and audio warnings (Wheale, 1983) improve reaction times significantly. Schepers' Computerised Information Processing Test Battery uses visual cues in the case of Form discrimination time and Colour discrimination time. Future measures should include audio cues, alphanumeric stimuli and other sensory stimuli to measure the influence of these stimuli on reaction time and rate of information processing.

As mentioned earlier, the number of stimuli in both the Rate of information processing (Perceptual) and Rate of information (Conceptual) tests were reduced to 60 stimuli per test. These two tests did not yield statistically significant differences between pilots and non-pilots, as indicated in Table 5. A future study should use the full-length version of these tests to ascertain whether the reduced form of the tests were less effective.

An all-encompassing model for pilot selection should include personality measures such as field dependence-independence, internal-external locus of control, emotional stability and introversion-extroversion. In addition to this, primary mental abilities such as verbal and numerical reasoning should be included together with psychomotor measures related to Choice reaction time, Form discrimination time, Colour discrimination time, Rate of information processing (Perceptual), Rate of information processing (Conceptual) and hand-eye co-ordination. Furthermore, neuropsychological measures, such as the EEG and evoked potentials of the brain, could also be considered for inclusion in the selection test battery for pilots.

The assumptions underlying discriminant function analysis were not completely met insofar as the variance-covariance matrices of the two groups differed statistically significantly. Therefore, the results should be cross-validated on a future sample before too much reliance is placed on the outcome of the present study.

\section{REFERENCES}

Bennett, S. \& Bowers, D. (1976). An introduction to multivariate techniques for social and behavioural science. London: Macmillan.

Braune, R. \& Wickens, C. D. (1986). The functional age profile: An objective decision criterion for the assessment of pilot performance capacities and capabilities. Human Factors, 27, 681-693.

Brown, I.D. (1966). Effects of prolonged driving upon skill and performance of a subsidiary task. Industrial Medicine and Surgery, 35, 760-765.

Burt, J. L., Bartolome, D. S., Burdette, D. W. \& Comstock Jr., J. R. (1995). A psycho-physiological evaluation of the perceived urgency of auditory warning signals. Ergonomics, 38, 2327.

Cliff, N. (1987). Analyzing multivariate data. Florida: Harcourt Brace Jovanowitz.

Cummings, R.W. (1964). The analysis of driving skills. Journal of the Australian Road Research Board, 1, 4-14. 
Fontana, D. (1990). Managing Stress. London: BPS Books/Routledge

Gagné, R. M. (1985). The conditions of learning and theory of instruction. (4th ed). New York: Holt, Rinehart \& Winston.

Gagné, R.M. (1965). Psychological principles in system development. New York: Holt, Rinehart \& Winston.

Geis-Alvarado \& Associates, Inc. (1997). Essentials of mishap prevention. South African Air Force. Napa: The International Safety Institute.

Gerbert, K. \& Kemmler, R. (1987). The causes of causes: Determinants and background variables of human factor incidents and accidents. Ergonomics, 29, 1439-1453.

Harris, R. (1997). Biases affecting information processing. http://www.sccu.edu/faculty/RHarris/infobias.htm.

Hick, W.G. (1952). On the rate of gain of information. Quarterly Journal of Experimental Psychology, 4, 11-26.

Hyman, R. (1953). Stimulus information, a determinant of reaction time. Journal of Experimental Psychology, 45, 188-196.

Jonsson, J. E., \& Ricks, W.R. (1993). Pilots' cognitive representations of flight deck information categories and priorities. http://www.larcpubs.larc.nasa.gov/randt/1993/RandT/SectionA/A 38html.

Kantowitz, B.H. (1974). Human information processing: Tutorials in performance and cognition. Mahwah: Lawrence Erlbaum.

Koonce, J.M. (1996). Aviator Selection. International Journal of Aviation Psychology. 6, 1-104.

Krantz, D.H., Luce, R.D. Atkinson, R.C. \& Suppes, P. (1974). Contemporary developments in mathematical psychology: learning, memory and thinking. Volume 1. San Francisco: Freeman.

Lachmann, R., Lachmann, J.L. \& Butterfield, E.C. (1979). Cognitive psychology and information processing. Mahwah: Lawrence Erlbaum.

Louw, D.A. (1989). Inleiding tot die psigologie. ( $2^{\text {nd }}$ ed.Tweede Uitgawe). Johannesburg: Lexicon.

Louw, D.A. \& Edwards, D. J. A. (1993). Sielkunde, 'n inleiding vir studente in Suider-Afrika. Johannesburg: Lexicon.

Malcolm, R. (1984). Pilot disorientation and the use of peripheral visual display. Aviation, Space and Environmental Medicine, $55,231-238$

Matlin, M. W. (1994). Cognition (3rd. Ed.). Orlando: Harcourt Brace.

Miller, G. A. (1953). The magical number seven, plus or minus two: some limits to our capacity for information processing. Psychological Review, 63, 87-91.

Miller, G. A. (1953). What is information measurement? American Psychologist, 8, 3-11.

Miller, G.A., Galanter, E. \& Pribram, K.H. (1960). Plans and the structure of behavior. New York: Holt, Rinehart \& Winston.

M-TWO, Italy. (1998). Cassiopea. http://www.mtwo.it/w4avps.htm.

Plug, C., Meyer, W.F., Louw, D.A. \& Gouws, L.A. (1989). Psigologie woordeboek. Johannesburg: Lexicon.

Posner, M. I. (1986). Chronometric explorations of mind. New York: Oxford University.

Remington, R. J. (1971). The effects of advance information on human information processing in a choice reaction time task. Psychonomic-Science, 24, 171-173.

Robinson Helicopter Company. (1981). Robinson R22: Pilot's operating handbook. Torrance: Robinson Helicopter Company.

Roscoe, S.N. (1980). Aviation psychology. Iowa: Iowa State University.

Schepers, J. M. (1974). Human factor limitations in flying with special reference to information processing. SAAPA, '74 Air Safety Symposium, The accident-sensitive area, Jan Smuts Holiday Inn, 3-4 May.
Schepers, J. M. (1987). Tempo van inligtingverwerking, spoed en padongelukke. Johannesburg: R.A.U.

Schepers, J. M. (2001). Manual of the computerised information processing test battery. Johannesburg: R.A.U.

Shub, Y., Ashkenazi, I. E. \& Reinberg, A. (1997). Differences between left- and right hand reaction time rhythms: indications of shifts in strategies of human brain activity. Cognitive Brain Research, 6, 141-146.

Schweizer, K. (1996). The speed-accuracy transition due to task complexity. Intelligence, 22, 115.

Schweizer, K. (1998). Complexity of information processing and the speed-ability relationship. Journal of General Psychology, $125,89$.

Shingledecker, C. A. (1979). The effects of anticipation on performance and processing load in blind mobility. Ergonomics, 21, 355-371.

Simon, J. R. \& Slaviero, D. P. (1975). Differential effects of a fore period countdown procedure on simple and choice reaction time. Journal of Motor Behavior, 7, 9-15.

Simpson, C. A., \& Marchionda-Frost, K. (1985). Synthesised speech rate pitch effects on intelligibility of warning messages for pilots. Human Factors, 26, 509-517.

Svensson, E., Angelborg-Thanderz, M., Sjoberg, L. \& Olsson, S., (1997). Information complexity - mental workload and performance in combat aircraft. Ergonomics, 40, 362.

SPSS Inc. (1999). Base 10.0 applications guide. Chicago: SPSS

Swissair. (1999). Crew Resource Management. http://www2.swissaircrm.ch/HAD.html.

Tacq, J. (1977). Multivariate analysis techniques in social science research. From problem to analysis. London: Sage.

Van Tharp, K. (1978). Sleep loss and stages of information processing. Waking and Sleeping, 2, 29-33.

Vernon, P.A. (1987). Speed of information processing and intelligence. Norwood: Ablex.

Wheale, J. L. (1983). Evaluation of an experimental central warning system with a synthesised voice component. Aviation, Space and Environmental Medicine, 54, 517-523.

Williams, L. J. (1995). Visual field tunnelling in aviators induced by memory demands. The Journal of General Psychology, 122, 225.

\section{END Notes}

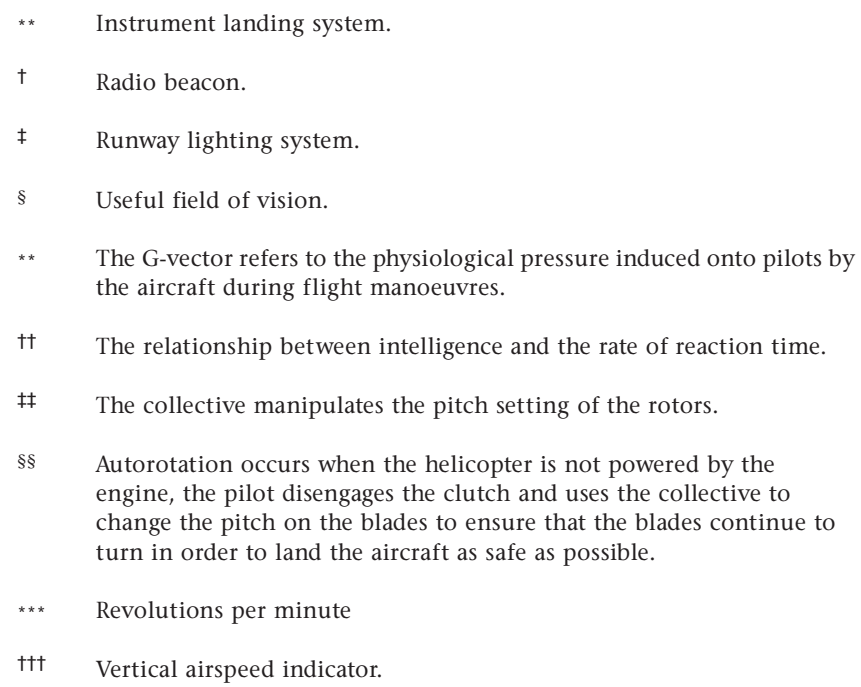

